OPEN ACCESS

Edited by:

Lyne Morissette,

M - Expertise Marine, Canada

Reviewed by:

Christian T. K.-H. Stadtlander, Independent Researcher, St. Paul,

USA

Mark Peter Simmonds,

University of Bristol, UK

Daniel K. Lew,

National Oceanic and Atmospheric

Administration, USA

*Correspondence:

Robert Harcourt

robert.harcourt@mq.edu.au

Specialty section:

This article was submitted to

Marine Affairs and Policy,

a section of the journal

Frontiers in Marine Science

Received: 28 October 2016 Accepted: 16 February 2017

Published: 07 March 2017

Citation:

Hawkins ER, Harcourt R, Bejder L, Brooks LO, Grech A, Christiansen F, Marsh $\mathrm{H}$ and Harrison PL (2017) Best Practice Framework and Principles for Monitoring the Effect of Coastal Development on Marine Mammals. Front. Mar. Sci. 4:59. doi: 10.3389/fmars.2017.00059

\section{Best Practice Framework and Principles for Monitoring the Effect of Coastal Development on Marine Mammals}

\author{
Elizabeth R. Hawkins ${ }^{1,2}$, Robert Harcourt ${ }^{3 *}$, Lars Bejder ${ }^{4}$, Lyndon O. Brooks ${ }^{2,5}$, \\ Alana Grech ${ }^{6}$, Fredrik Christiansen ${ }^{4}$, Helene Marsh ${ }^{7}$ and Peter L. Harrison ${ }^{2}$
}

${ }^{1}$ Dolphin Research Australia Inc., Byron Bay, NSW, Australia, ${ }^{2}$ Marine Ecology Research Centre, Southern Cross University, Lismore, NSW, Australia, ${ }^{3}$ Department of Biological Sciences, Macquarie University, North Ryde, NSW, Australia, ${ }^{4}$ Cetacean Research Unit, School of Veterinary and Life Sciences, Murdoch University, Murdoch, WA, Australia, ${ }^{5}$ StatPlan Consulting Pty Ltd, Woodburn, NSW, Australia, ${ }^{6}$ ARC Centre of Excellence for Coral Reef Studies, James Cook University, Townsville, QLD, Australia, ${ }^{7}$ College of Science and Engineering, Centre for Tropical Water and Aquatic Ecosystem Research, James Cook University, Townsville, QLD, Australia

As the world's human population increases along the coastal zone, with major alteration of coastal embayments, increased on-water activities and a plethora of other intrusions into the coastal zone, there is a simultaneous increase in pressures on marine mammals. Growing evidence indicates that many marine mammals are highly susceptible to declines resulting from direct and indirect impacts arising from diverse human activities. Too frequently, assessment of the impact from coastal developments on marine mammals has been inadequate or completely lacking. At worst this has led to catastrophic decline in some populations. Without rigorous ecological assessments along with adaptive management frameworks prior to the initiation of developments, the number of marine mammal populations likely to be adversely impacted will continue to rise. To address these shortcomings, we present a globally applicable best practice framework by; (i) describing guiding principles and; (ii) reviewing appropriate procedures for assessment and monitoring of impacts of coastal developments on marine mammals. The approach outlined is embedded in Environmental Impact Assessment processes as a means by which decision makers and stakeholders can be informed. Recommendations presented are designed to encourage the application of robust scientific evaluation that applies appropriate survey design with sufficient statistical power to detect changes before trigger thresholds are reached. We emphasize that there is an urgent need to ensure assessments are comprehensive, effective and integrated with monitoring and adaptive management actions in order to minimize or effectively mitigate the impacts of human activities on marine mammal populations.

Keywords: environmental impact assessment, monitoring, mitigation, cumulative impacts, short term impacts, long term impacts 


\section{INTRODUCTION}

Development and transformation of coastal areas by humans has accelerated dramatically in recent times (Lotze et al., 2006) with over $40 \%$ of the world's population living close to the coast and further migration to coastal areas predicted (Small and Nicholls, 2003). This pattern of human occupation coupled with the increased demand for resources and trade, places considerable pressure on coastal biota and ecosystems (Lotze et al., 2006). Development along the coastal fringe and catchments relating to infrastructure, industrial, urban, port, shipping, fishing/aquaculture, tourism industries and other activities leads to multiple and diverse alterations in the environment over relatively short (days-months) to long-term (years-decades) time-scales (Castilla, 1999). These alterations can lead to extensive changes in coastal habitats through, for example, increased ambient noise, land reclamation, increased sedimentation, increased nutrient and pollutant loads, changes in environmental processes and the intensification of human activities such as boating and fishing (Frihy, 2001; Evans, 2009; Jefferson et al., 2009). These activities and environmental changes often result in behavioral, physiological and ecological changes to some species and/or extensive changes to their prey and habitat availability, which can cause long-term population effects (Cubero-Pardo et al., 2011). In the absence of effective mitigation, detrimental impacts on wildlife from human activities can cause permanent and irreversible change.

Higher order animals such as marine mammals are particularly vulnerable to exposure from human activities. Such exposure can lead to many direct and indirect impacts including; temporary or permanent movement away from core habitats (Watson-Capps and Mann, 2005; Bejder et al., 2006b), disturbance to critical behaviors resulting in alterations to energy budgets and vital rates (Steckenreuter et al., 2011; Christiansen and Lusseau, 2015), increases in fishing interactions (Read, 2008; Mannocci et al., 2012; Allen et al., 2014), depletion in prey availability and increased competition for resources (Harwood, 2001), entanglement and ingestion of foreign debris (Harcourt et al., 1994; Page et al., 2004), disruption to acoustic communication systems with possible physiological damage to hearing abilities [Temporary Threshold Shift (TTS) and Permanent Threshold Shift (PTS)] (Richardson et al., 1995; Foote et al., 2004; Tyack, 2008; de Souza Albuquerque and da Silva Souto, 2013), increases in injury and mortality from vessel strikes (Wells and Scott, 1997; Laist et al., 2001; Panigada et al., 2006), bioaccumulation of toxins leading to immunosuppressant symptoms (Jepson et al., 2005; Litz et al., 2007; Cagnazzi et al., 2013a), reproductive collapse (Jepson et al., 2016), cerebral impairment (Cook et al., 2015), incidence of disease (Van Bressem et al., 1999) and the introduction of new parasites and pathogens (Delport et al., 2014, 2015). The effect of these impacts upon populations of marine mammals, particularly where cumulative pressures are present, can lead to population-level consequences resulting in long-term shifts in habitat suitability, lower reproductive success, decreased health, increased mortality and population declines (Zhang et al., 2003; Lusseau, 2004; Wang et al., 2006; Bejder et al., 2006b; Pirotta et al., 2013; Cagnazzi et al., 2013b; Christiansen and Lusseau, 2015).

Marine mammals have diverse life histories and occupy a variety of habitats from rivers and estuaries to open ocean. Whilst some are highly mobile and migratory, others occupy specific home ranges for at least some of their life cycle (Brakes and Dall, 2016). Some species exhibit matrilineally learned behaviors which can make their use of space very conservative (Marsh et al., 2011). This results in different responses to disturbances at the levels of species, populations and habitat type (Harwood, 2001; Brakes and Dall, 2016). Many populations of coastal marine mammals have experienced significant declines due to cumulative impacts of human activities and developments, with the most vulnerable being those with small populations and high site fidelity occupying localized areas that are impacted by development (Lusseau et al., 2006; Schipper et al., 2008).

The potential impact of development is illustrated by three recent examples. First, the endangered southern resident orca (Orcinus orca) community of the Northern Pacific has experienced a near 20\% population decline between 1995 and 2001 (Krahn et al., 2002; Ford et al., 2010). Second, drastic declines over the past 30 years have also been detected in the now critically endangered Indo-Pacific humpback dolphin (Sousa chinensis) populatin of Taiwan (Wang et al., 2007; Reeves et al., 2008). Third, and worst, is the recent extinction of the Baiji (Lipotes vexillifer) throughout its range (Turvey et al., 2007). Each of these declines has been directly attributed to cumulative pressures from industrial activities and the exposure to threats associated with fisheries interactions, reduction in prey availability, increases in vessel traffic, pollution (including noise) loads and construction activities along with habitat degradation and habitat reduction (Ross, 2006; Wang et al., 2006, 2007; Williams et al., 2006; Turvey et al., 2007; Reeves et al., 2008; Lusseau et al., 2009; Williams and O'Hara, 2010).

These three examples demonstrate the potential severity of the consequences of cumulative, multi-pathway impacts and pressures that human activities and development can place on marine mammal populations inhabiting coastal areas. Accordingly, it is imperative that processes, assessments and management be improved and informed by appropriate, robust and integrated advice. Environmental Impact Assessments (EIA) are an integral component of the decision making process as they quantify the potential adverse consequences of coastal development on biodiversity and identify measures to avoid, mitigate or offset impacts established (Vlachos, 1985). EIAs allow for evaluations to be made prior to the commencement of a project. In addition, EIAs can identify and describe compliance monitoring programs to measure the impact of approved coastal developments and enable adaptive management measures. In many countries, EIA processes have been incorporated into and regulated through legislation such as the National Environmental Policy Act (NEPA) 1970 of the United States, the Canadian Environmental Assessment Act 2012, Environment Conservation Act 1989 of South Africa, the Environmental Quality Act 1974 of Malaysia, the Resource Management Act 1991 of New Zealand and the Environment Protection and 
Biodiversity Act (EPBC) 1999 of Australia (Gilpin, 1995; Elliott, 2014).

The requirements and governance of EIAs currently provide the primary means to ensure the integrity and preservation of vulnerable species and their habitats. Under EIA legislation, the onus and responsibility is placed on both developers and decision makers to minimize the adverse impacts associated with activities on the environment (Elliott, 2014), particularly areas of critical importance, species of special interest or species of high conservation priority (Jefferson et al., 2009; Tyne et al., 2015). Marine mammals typically trigger the last two criteria. Weighing up the costs and benefits of development projects and subsequent activities presents a challenge to decision makers who must take into consideration the economic, social and environmental impacts that occur during each of the pre-construction, construction, post-construction or operational phases (Wood, 2003). Complexities may also arise due to cross-jurisdictional boundaries and the need for multi-agency involvement and this can increase tensions due to the differing objectives, agendas and interests between these bodies (Grech et al., 2013; Braulik et al., 2015). Political, economic and social pressures can add to this challenge. Historically economic gain has been prioritized over the environment, and developments can occur without sufficient consideration, mediation or offsetting of impacts (Wang et al., 2007; Jefferson et al., 2009).

Decision makers and proponents should be informed by rigorous scientific evaluations that robustly predict the possible effects of development activities on the biota and ecosystems or habitat of concern. These evaluations, for example, can be presented as an Environmental Impact Statement (EIS) that constitutes one component of the EIA process in the Australian Commonwealth (Elliott, 2014). Yet in many cases, where coastal developments and marine mammals "meet," management and regulatory decisions are made in the absence of sufficient or appropriate data (Grech and Marsh, 2008; Bejder et al., 2012). Inappropriate application of methods may also occur (Bejder et al., 2012). For example, making assumptions regarding the presence and abundance of a dolphin species using a low number of samples obtained from a few opportunistic sightings is not likely to confidently determine the impacts of a coastal development (Tyne et al., 2016).

There is currently little consensus as to the most appropriate approach to evaluate the potential impacts from development projects (pre-approval) on marine mammals through the EIA process nor approaches to monitoring the impacts during the construction and operational phases of an approved development. This is despite such monitoring often being a condition of development approval. We suggest that the optimal approach to providing robust and relevant data for assessing the potential and actual impacts of coastal development projects requires standardized practice. We present a globally applicable framework for the best practice principles for effective monitoring to minimize the impacts of coastal developments and associated activities on marine mammals. The framework consists of guiding principles and reviews procedures for assessment and monitoring. The approach made is embedded in commonly used procedures within EIAs (e.g., Elliott, 2014) and specifically focuses ecological components and expands on those elements most relevant to marine mammals. The social and economic components of EIA are beyond the scope of this paper.

This framework was informed by discussions amongst experts and participants in a workshop held in association with the 20th Biennial Conference on the Biology of Marine Mammals in 2013, along with published literature and the collective experience of the authors. The aim of the framework is to outline approaches that underpin best practice and describe standardized methods to assess the potential and actual impacts of coastal developments on marine mammals. The workshop consisted of eight presentations from seven experts in marine mammal monitoring who provided detailed information on available methods and appropriate application of techniques. These presentations were then workshopped by the 57 attendees from nine countries to assess and monitor impacts for a number of different hypothetical coastal developments (e.g., tourism, port, urban developments, and seismic activities) in the developed and developing world. Discussions focused on appropriate survey design, limitations and recommendations from the attendee's personal experiences. The following sections outline the consensus of these discussions as guiding principles and a review of procedures relevant to the design, assessment and monitoring of marine mammals in relation to the pre, during and post or operational phases of a development project.

\section{MONITORING FOR A PURPOSE: BEST PRACTICE FRAMEWORK}

Determining the most effective approach to detect and monitor the potential and actual impacts of coastal development on often highly mobile marine mammals in a dynamic coastal environment will be influenced by many different factors. The approach selected will invariably be constrained by available time and resources, locality and form of development. The approach will also need to be customized as appropriate to the distribution, abundance and ecology of species present. Despite these constraints, there are strong underlying principles which are generally applicable, that we discuss below.

\section{Guiding Principles for Assessments}

The intent of the principles presented here is to provide guidance during assessment and decision-making processes in regards to impacts of coastal development on marine mammals. These principles are intended to guide industry standards to minimize adverse biological and ecological impacts on marine mammals and trigger management responses when acceptable levels of impact are exceeded. These principles are derived from the extensive experience and expert opinion of the authors and workshop participants combined with those outlined by the International Association for Impact Assessment, a leading network on best practice for impact assessment (Senécal et al., 1999). In agreement with Dolman and Simmonds (2010), we recommend out the outset that EIAs be utilized as an essential tool wherever possible in order to apply appropriate methods and 
monitoring during different stages of development which can be overseen by management actions.

Ecological assessments and monitoring associated with the determination of the impacts on marine mammals from coastal developments should be designed to meet the following principles:

- Avoid biologically significant negative impacts on marine mammal populations, communities, the habitats and ecosystems on which they rely.

- Apply appropriate, systematic and rigorous assessment procedures that address the relevant scope of the project during all phases of development and operation.

- Present accurate information regarding the likelihood and significance of potential impacts that may arise as a direct result of proposed activities with information about the statistical power and limitations.

- Provide scientific advice as a sound basis for decision making and adaptive management responses to avoid and mitigate impacts on the environment and to ameliorate unavoidable impacts.

\section{Ecological Assessment Procedures}

With these principles in mind, there are a number of steps in the process of assessing and then addressing the potential risks and impacts from developments that can be followed. Figure 1 presents a conceptual model of these steps building on the general EIA process outlined by Elliott (2014), and expanding on those steps relevant to ecological assessments involving marine mammals. This figure outlines nine steps for designing and evaluating the impact of developments on marine mammals as it relates to the different phases (pre, during and operational). The steps are interdependent as demonstrated by the feedback loops (Figure 1). Initially, EIAs are generally informed by policy and legislation which denote the need for the assessment. The requirements for an EIA are typically defined in the relevant legislation and thus differ between jurisdictions. Where policy determines that an EIA process is necessary, for example, if a project or associated activity may significantly impact marine mammals, particularly vulnerable species and populations, an investigation into the scope of the impacts and risks is required. In some cases, this is presented as an EIS. For example, in relation to the Australian Commonwealth, steps 1-6 in Figure 1 may specifically relate to the EIS component of the EIA and provide essential input into the decision making processes, i.e., whether a project is approved or declined. In the case of an approved project, the initial EIS will then set the direction for monitoring and management (steps 8 and 9) (Elliott, 2014). The following sections break down the different steps in more detail.

\section{Scoping Considerations and Identification of Risk Sources}

If an EIA is required, the first step involves planning, engagement and establishing available funding and resources. Information on the species, habitats and ecosystems that are likely to be affected by the proposed project activities need to be reviewed and the spatial extent of the impact zone, as well as the time period over which the activity is conducted need to be considered. What species are likely to be present and persist in the impact zone and surrounding areas? What is the current conservation status of these species in the jurisdiction and in the impact zone? Is the site appropriate for development?

Marine mammal species are diverse and some species are far more vulnerable to adverse impacts from particular activities due to their life history parameters, population size, restricted usage areas, site fidelity and/or social system (Hawkins and Gartside, 2008; Wade et al., 2012; Cagnazzi et al., 2013b; Brakes and Dall, 2016; Smith et al., 2016). For example, a small localized population of coastal dolphins that uses habitats in the vicinity of an impact zone to perform critical tasks (e.g., feeding and reproduction) on a daily basis is likely to be more susceptible to associated risks from the activity, such as the bioaccumulation of pollutants, or repeated disturbance to important behaviors, than a migratory species that has transitory exposure to the pollutant or disturbance factor. The likely exposure to and effects of each disturbance factor need to be addressed along with the potential interactions and synergistic effects from project activities. For example, shipping noise is a by-product of port developments. Thus, increased shipping activity and noise during both the construction and operational phases of a development potentially have widespread impacts over long time periods (Erbe, 2012). Furthermore, Dolman and Simmonds (2010) highlight that developments should not occur in protected areas or areas of critical importance to cetacean populations.

\section{Defining Goals and Objectives}

Second, the goals and objectives of the monitoring program must be clearly specified. In agreement with Block et al. (2001) it is recommended that these objectives be specific to the project, feasible and achievable and stated clearly. The goals can be broadly expressed in general terms but must be concerned with minimizing the impact of activities associated with the development on the species of interest. The objectives should more explicitly relate to hypotheses to be tested or be a statement of the desired reference conditions. A clear description of the terms of reference and conditions to be met should also be stated (Block et al., 2001). For example, objectives may specify that the project activities will not reduce the area of occupancy of a particular dolphin population.

\section{Approach and Methodology: Choosing Appropriate Methodologies}

The third step is to determine the best approach to attain robust and relevant data in the context of the inevitable constraints on resources coupled with the difficulties in studying free-ranging marine mammals. Should the populations, habitats or both be measured and monitored? The appropriate methods for marine mammals will usually address abundance, occupancy, habitat usage, health (i.e., body condition) and behavioral patterns during each phase of operation.

Power analysis can be performed to assist in determining appropriate sampling effort. This is particularly useful when dealing with species that are rare or have low detection probabilities and where budgets are limited (Wilson et al., 


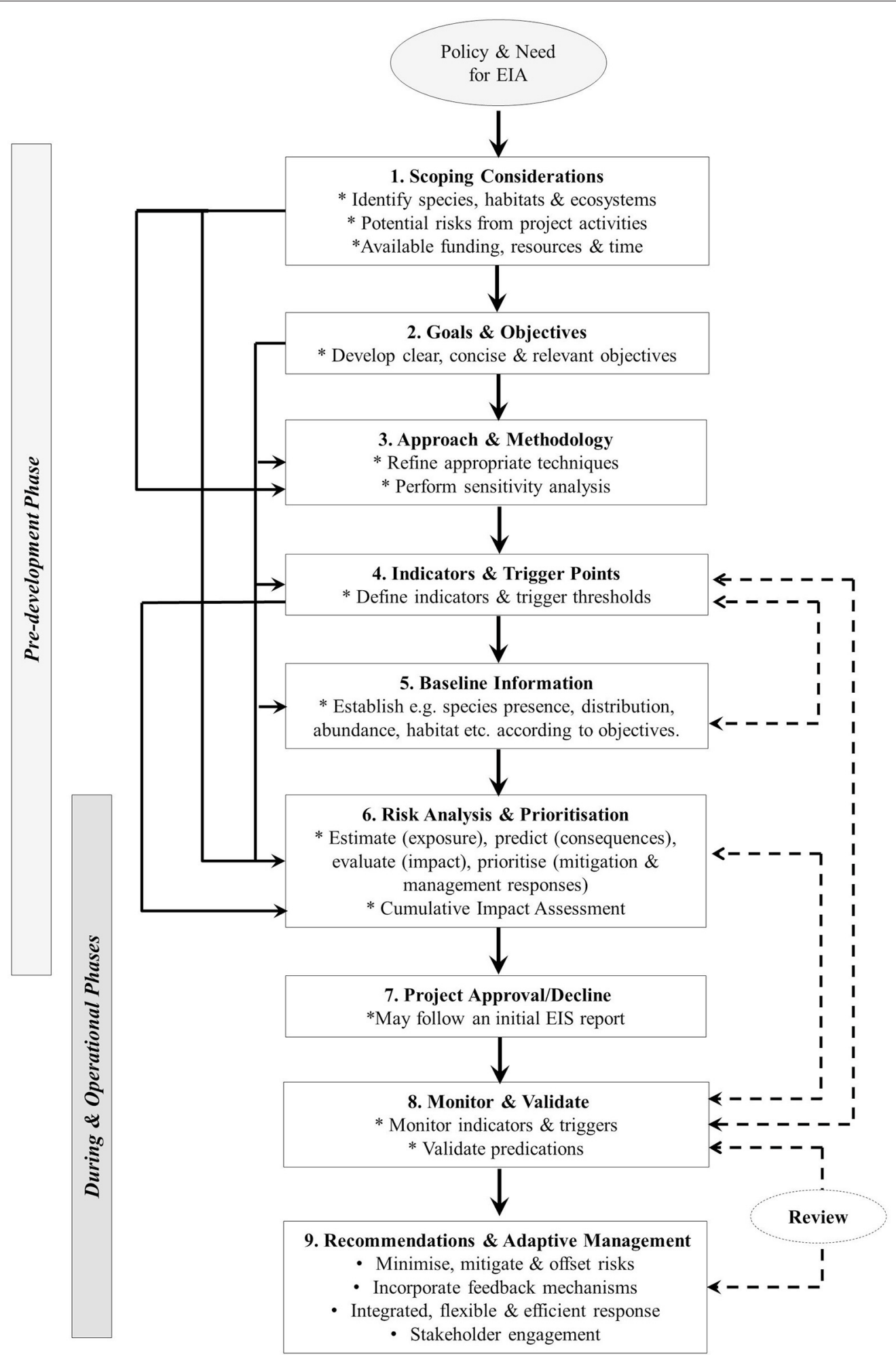

FIGURE 1 | Steps and procedures associated with the design, ecological assessment, and monitoring of environmental impacts relevant to coastal developments on marine mammals and feedback mechanisms with respect to each phase of construction and operation. Note: dashed lines indicate feedback loops. 
1999; Taylor et al., 2007; Tyne et al., 2016). Information from empirical research on the same or similar species can provide Supplementary Data to inform power analysis. Detection probabilities can be influenced by species, sample effort, environmental conditions, time, observers, abundance and sites (Moore and McCarthy, 2016). Determining the probability of detection against costs/budget, time and effort, can assist in determining the necessary trade-offs between these factors to achieve the best outcomes (see Hauser and McCarthy, 2009; Moore and McCarthy, 2016; Tyne et al., 2016). The optimal sampling effort will be driven by the specific objectives and the indicators selected for monitoring.

While empirical information can be used to ascertain the potential presence of a species during the scoping phases of an EIA, establishing actual presence can usually only be determined by onsite sampling. The workshop consensus indicated that survey design include areas where the habitat is believed to be both suitable and unsuitable for the species whilst taking into consideration appropriate spatial and temporal sampling periods to avoid bias. For example, different sampling periods are likely to be necessary if the species is migratory vs. resident.

Application of appropriate methods is essential from the outset to establish the presence and abundance of populations within the impact zone. The sample design will typically use the Before-After-Control-Impact (BACI) quasi-experimental approach (Block et al., 2001). However, it can be difficult to determine if a change in abundance or habitat use of a marine mammal is caused by an impact related to a development or outside influences or a combination of factors (Lotze et al., 2006; Crain et al., 2008). For example, is a decline in abundance in the impact zone a direct result of the project activities or natural variation? Control sites may be useful in helping to separate impacts from natural variation. Underwood (1994) argues that, without at least two control sites, it is almost impossible to gain a clear indication of whether observed changes are attributable to the activities of a project or natural variation. Careful selection of control sites is necessary to ensure that they have very similar environmental components to a "treatment" site and be sufficiently geographically distant to ensure independence (Block et al., 2001). That often little is known about the rate, pattern or extent of movement of coastal marine mammals and that coastal environments may be highly variable, mean that pseudoexperimental study designs of marine mammal populations may rarely yield the standard of evidence that might be expected of a randomized, controlled trial. Their high mobility, cryptic behavior, often low density and marine environment contribute to very high expenditures of funds and sampling effort if estimates for many marine mammals are to be obtained with suitable precision (Taylor et al., 2007). True control sites are extremely difficult to identify for marine mammals and while BACI methods are the norm in experimental research, attempts to set up pseudo experimental designs for populations of highly mobile marine mammals may fail to meet experimental design criteria in view of the potential for movement between similar sites, natural variation in population dynamics parameters and naturally varying environmental conditions. Intensive study of control sites in an effort to replicate an experimental design may not be the most productive application of resources in view of the objectives of a study when the strict conditions expected in experimental design are unlikely to be achieved. We recommend that pseudo experiments only be conducted when suitable controls can be established and power analysis indicates that a design is likely to meet the criteria for statistical and ecological significance.

Table 1 outlines some of the commonly used methods that relate to addressing the key measures of abundance, occupancy, habitat usage, health and behavioral patterns. These methods have a number of advantages and disadvantages which are also listed in Table 1. Below we further discuss methods related to presence and abundance of marine mammals to provide an example of some of the considerations that should be taken into account when comparing different approaches for a commonly required component of assessments.

To determine the presence and abundance of populations within a given area, three techniques can be applied: occupancy, mark-recapture and distance-sampling models. An advantage of presence/absence or count surveys is that that are significantly less expensive per unit area than capture-recapture methods and the latter in any case may well not be feasible. Consequently, a relatively large area can be monitored for presence/absence or counts for the same total cost as a smaller area for capturerecapture surveys. While occupancy models (e.g., MacKenzie et al., 2006) may seem to offer a very efficient way to provide a snapshot of marine mammal distribution and the probability that they occupy certain types of habitats throughout their range, a critique of occupancy in continuous habitat by Efford and Dawson (2012) suggest that occupancy models may not always be informative. Occupancy is ill-defined when site sizes are arbitrarily defined in continuous habitat relative to the typically unknown home range sizes of marine mammals and estimates of the probability of occupancy by habitat types may amount to no more than estimates of relative density. In that case, it may be preferable to employ models (e.g., generalized additive models Wood, 2006) to estimate relative density directly.

Furthering this example, one of the challenges of estimating the relative or absolute abundance of marine mammals in the coastal zone is the heterogeneity of the associated detection probabilities. These animals spend much of their time below the surface of the water and often occur in waters in which the in-water visibility can vary in a few minutes within a single transect from clear with the bottom visible and all animals potentially available, to turbid so that only animals at the surface are visible. Many variables may prevent a survey observer from detecting a marine mammal including its diving behavior, weather conditions such as glare and cloud cover, sea state, water turbidity and observer inexperience or fatigue (Marsh and Sinclair, 1989; Pollock et al., 2006). Marsh and Sinclair (1989) recognized that the probability of detecting marine mammals that are present in a survey area has two components: (1) the probability of an animal being near enough to the surface to be seen by an observer (availability bias); and (2) the probability of an animal being detected and counted by an observer, given that the animal is available (perception bias). 
TABLE 1 | Appropriate use, advantages and disadvantages of the most commonly applied methodologies for assessing the abundance, presence and absence and behavioral responses of marine mammals to disturbance.

\begin{tabular}{|c|c|c|c|}
\hline Method & Use & Advantages & Disadvantages \\
\hline $\begin{array}{l}\text { Occupancy models and area } \\
\text { sampling }\end{array}$ & $\begin{array}{l}\text { Occupancy models estimate the } \\
\text { proportion of sites that are occupied by } \\
\text { the species, or the probability of } \\
\text { occupancy as a function of habitat } \\
\text { covariates. } \\
\text { The cluster sampling principle (sites, } \\
\text { replicate surveys per site) inherent in } \\
\text { occupancy studies may be manageable } \\
\text { and efficient for surveys over large } \\
\text { areas especially remote areas. If } \\
\text { sighting width from transect is known, } \\
\text { these "sighting surveys" are an example } \\
\text { of area sampling. }\end{array}$ & $\begin{array}{l}\text { - Much larger areas can be surveyed for } \\
\text { presence/absence or counts than for } \\
\text { abundance by capture-recapture. } \\
\text { - Area sampling is useful for estimating the } \\
\text { distribution of a species over very broad } \\
\text { scales. } \\
\text { - Non-detection needs to be accounted for if the } \\
\text { objective is estimation of true density or } \\
\text { abundance rather than a consistent } \\
\text { underestimate or relative density. } \\
\text { - Methods for dealing with non-detection are } \\
\text { often associated with distance sampling. }\end{array}$ & $\begin{array}{l}\text { - Estimates of true density or abundance } \\
\text { - A conly if non-detection is accounted for. } \\
\text { density - may provide a useful } \\
\text { description of the spatial distribution of } \\
\text { a species. } \\
\text { - Occupancy models should not be } \\
\text { considered appropriate for surveys } \\
\text { conducted in continuous habitat when } \\
\text { site sizes are arbitrarily defined and } \\
\text { home range sizes are unknown. }\end{array}$ \\
\hline Mark-recapture models & $\begin{array}{l}\text { Estimate fundamental population } \\
\text { dynamics parameters in addition to } \\
\text { abundance, e.g., apparent survival (true } \\
\text { survival x site fidelity), recruitment } \\
\text { (births + immigrants), rate of change of } \\
\text { population size, temporary emigration. }\end{array}$ & $\begin{array}{l}\text { - Can provide additional information on behavior, } \\
\text { species distribution, habitat use and } \\
\text { movement patterns collected during surveys } \\
\text { for capture-recapture. }\end{array}$ & $\begin{array}{l}\text { - Expensive and intensive, therefore can } \\
\text { limit size of survey area } \\
\text { - Time consuming } \\
\text { - Can be sensitive to misidentification of } \\
\text { individuals }\end{array}$ \\
\hline Distance sampling & $\begin{array}{l}\text { Estimates the density and/or } \\
\text { abundance of populations using line or } \\
\text { point transects. }\end{array}$ & $\begin{array}{l}\text { - Can cover large spatial ranges and multiple } \\
\text { species } \\
\text { - Can be done in association with other surveys } \\
\text { - Population or species effects can be detected, } \\
\text { e.g., changes in abundance, movement, } \\
\text { health effects, behavior etc. } \\
\text { - Provides robust results when studies are } \\
\text { designed properly }\end{array}$ & $\begin{array}{l}\text { - Can be expensive } \\
\text { - Weather dependent } \\
\text { - If assumptions of distance sampling } \\
\text { are violated (e.g., animals approach } \\
\text { or avoid vessel before detection), the } \\
\text { resulting biases can be difficult to } \\
\text { quantify } \\
\text { - Correcting for heterogeneous detection } \\
\text { bias requires considerable work } \\
\text { external to the survey. }\end{array}$ \\
\hline
\end{tabular}

\section{Passive acoustic sampling Provides the ability to monitor and} and monitoring

locate the presence/absence of animals, habitat use, temporal and spatial patterns using passive acoustic detectors.

Monitor for physiological impact thresholds (TTS, PTS*), masking and impacts on prey species.
- Cost effective

- Not dependent on weather, daylight

- Monitor for a longer time, in locations unsuitable for visual surveys

- Detectability of species that are difficult to observe
- Sound transmission can be affected by many factors

- Species recognition difficult for some species

- Acoustic activity depends on behavior, in particular, the rate of individual vocalization may depend on density

- Determining number of individuals and group size can be difficult

\section{Behavioral Sampling Provides the ability to visually monitor} and locate the presence/absence of animals, habitat use, temporal and spatial patterns, activity budgets using behavioral observations.

Detection of short term responses. Exposure to activities, levels of human interactions and habituation can also b examined. Detection of physiological changes
- Can be done in association with other methods, e.g., acoustic and mark-recapture sampling

- Provides demographic information on population parameters, habitat use, species distribution etc.

- Can provide information on the activity budget.

- Can be cost effective (e.g., land-based surveys)

- Can use different platforms and integrated into other assessments, e.g., abundance surveys
- Often based on short-term samples which are difficult to relate to long-term changes or impacts

- Time consuming and can be expensive (e.g., vessel-based surveys and analysis)

- Many variables can effect behavior, e.g., history of individuals and habituation levels
- Relates directly to individual survival and reproduction.

- Allows comparison with healthy (undisturbed) populations.

- Can be cost effective (e.g., drones).

- Can also be used to record the presence of body injuries.
- Provides a relative rather than absolute estimate of health.

- Weather dependent.

- Can be invasive (e.g., ultrasound measurements of blubber thickness).

- Monitoring is time consuming.

- Sensitive to measurement errors.

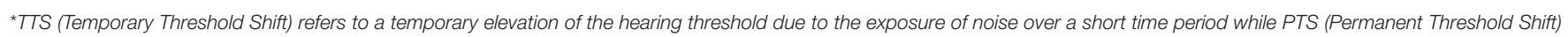
refers to permanent hearing loss due to prolonged exposure to noise (Richardson et al., 1995). 
Distance sampling (Buckland et al., 2005) is another approach that provides another example for consideration. Distance sampling assumes that all animals on the survey line are detected, i.e., $g(0)=1$. However, this assumption is likely to be untrue for diving mammals, making absolute abundance difficult to estimate using survey techniques. Using relative abundance as a robust index of abundance requires the alternative assumption that $g(0)$ is constant. Examples of sophisticated aerial survey methods that deal with non-detectability (availability bias) include a survey of a density surface model on Pantropical spotted dolphins in the Gulf of Mexico (Miller et al., 2013), Hectors' dolphin (MacKenzie and Clement, 2014) and work on the diving patterns of dugong (Pollock et al., 2006; Hagihara et al., 2014). These examples exemplify the challenges that may be faced when selecting the most appropriate survey methods and the research that needs to be done external to a survey to test the underlying assumptions.

Using direct measures and observations of populations is the most straightforward approach to addressing the responses and impacts of activities (Block et al., 2001), but the cost of measuring single-species responses can be high and most likely will exceed available project budgets (Block et al., 2001). Monitoring habitat and prey species as surrogate measures of impacts on populations can be less costly, however, the relationships between habitat and marine mammal species are often largely unknown and may vary between regional areas and over time. Thus, relying solely on monitoring of habitat as a surrogate measure to address the impact of activities on most marine mammals is likely to introduce unwanted sources of uncertainty (Block et al., 2001). By only monitoring habitat variables, e.g., seagrass coverage, impacts such as changes in occupancy, physical health, or vital rates of the population can be missed. A combined approach may prove both effective and economical whereby causal pathways and cumulative assessments can also be more effectively addressed.

\section{Indicators and Trigger Points}

A variety of indicators and trigger points can be used for assessing the impacts of coastal development on marine mammals. The indicators and triggers selected will be project specific and informed by the species and its conservation status, habitat type, the ecological relationships between species and habitat features, and the type of development and associated activities. In this context an indicator is a measure that can be related to the vital rates or other factor of concern for a community or population (Scholes and Kruger, 2011; Fleishman et al., 2016). Hence, a critical component to consider when selecting indicators and trigger points is the pathway through which measurable effects (e.g., behavioral changes) can influence vital rates (or other factors of concern). Equally important is the need to identify the parameters required to inform such relationships, and focus research efforts and resources to determine and monitor those parameters.

The type of risk, whether direct or indirect and lethal or sublethal, will influence the pathway and number of parameters needed to evaluate the consequences of that risk (Christiansen and Lusseau, 2015). For example, vessel traffic can have both direct and indirect effects on marine mammal populations.
Vessel collisions (a direct impact) can injure and kill marine mammals, which at worst may negatively affect population trajectories (Wells and Scott, 1997; Laist et al., 2001; Panigada et al., 2006). To quantify this effect, direct observations, reporting or model simulation can be used. Behavioral and/or physiological disturbance may also influence energetics (energy intake and expenditure), which over time can influence body condition, vital rates, and ultimately population dynamics (Christiansen and Lusseau, 2015; New et al., 2015). In such a scenario, monitoring can focus on select indicators such as behavioral response, body condition and vital rates (e.g., offspring production and survival) to vessel disturbance along with exposure and activity of vessels (e.g., Lusseau, 2004; Christiansen et al., 2013).

Careful consideration of how risks might influence populations is necessary when choosing which indicators to use in assessing impacts of a coastal development. The most useful indicators will be those for which there is sufficient understanding of causal relationships between factors and that can be measured effectively (Newson et al., 2009). For each indicator selected, an acceptable limit of change is then defined to inform the trigger points for monitoring and management responses. A trigger point or threshold in this case refers to the levels or values of change that the activity or project is attempting to achieve or avoid (Block et al., 2001). Defined limits of change preferably originate from knowledge of "true system thresholds" (Scholes and Kruger, 2011). It is recommended that these thresholds are re-assessed as part of the design of monitoring programs and feedback mechanisms. Table 2 lists some examples of the types of indicators and related triggers that result in detrimental impacts to the population of marine mammals. This list is by no means exhaustive and appropriate indicators and triggers will need to be determined based on the specific context of the development and objectives of the assessment with unambiguous levels of change specified to provide clear measures.

There are very few examples of environmental monitoring using empirically derived trigger points for marine mammals, due to the difficulties in defining a significant or biologically meaningful change and our limited knowledge of the relationships between most species and their habitats (Nie and Schultz, 2012). The slow life histories and delayed response to vital rates in marine mammal species adds an additional monitoring challenge as detection of a problem can arise long after thresholds have been crossed (Brakes and Dall, 2016). In light of these challenges, however, it is nevertheless important to ensure that acceptable/unacceptable changes and associated trigger points are clearly defined to inform pre-planned intervention measures. As Lindenmayer et al. (2013) emphasize, changes in indicators should be rigorously assessed as early as possible to avoid a population decline remaining undetected due to ineffective monitoring or slow and/or limited intervention. For example, survey effort may be required over multiple years to detect declines in populations, however, declines may occur well before sufficient power is ever attained (Taylor et al., 2007; Tyne et al., 2016). Changes to decision-making criteria may be necessary (Taylor et al., 2007) in the absence of sufficient resources or time to 
TABLE 2 | Examples of potential triggers and indicators for assessment and monitoring programs associated with determining the impact of coastal developments on marine mammals.

\begin{tabular}{|c|c|c|}
\hline Potential trigger* & Examples of indicators & Example references \\
\hline Behavioral change & $\begin{array}{l}\text { - Short term behavioral changes } \\
\text { - Long term behavioral changes }\end{array}$ & $\begin{array}{l}\text { Bejder et al., 2006a; Lusseau and Bejder, 2007; } \\
\text { Lusseau et al., } 2014\end{array}$ \\
\hline $\begin{array}{l}\text { Noise exposure potentially causing behavioral } \\
\text { disruption and physiological injury (TTS or PTS) }{ }^{\star \star}\end{array}$ & $\begin{array}{l}\text { - Changes in communication patterns } \\
\text { - Changes in the presence and movement of marine } \\
\text { mammals } \\
\text { - Changes in the presence and movement of prey } \\
\text { species } \\
\text { - Increase in mortality rates }\end{array}$ & $\begin{array}{l}\text { Bain and Dahlheim, 1994; Richardson et al., 1995; } \\
\text { Schlundt et al., } 2000\end{array}$ \\
\hline Damage to important, core or critical habitat & $\begin{array}{l}\text { - Decrease in the availability and health of habitats } \\
\text { - Alterations in the presence and health of prey species } \\
\text { - Displacement from habitat }\end{array}$ & $\begin{array}{l}\text { Bearzi et al., 2006; Bejder et al., 2006b; Hughes } \\
\text { et al., } 2009\end{array}$ \\
\hline Changes in spatial use & $\begin{array}{l}\text { - Alteration in the habitat use and presence of marine } \\
\text { mammals }\end{array}$ & Morton and Symonds, 2002; Bejder et al., 2006b \\
\hline $\begin{array}{l}\text { Declines in population vital parameters, e.g., } \\
\text { abundance, survival or fecundity }\end{array}$ & $\begin{array}{l}\text { - Decline in relative abundance, presence or density, } \\
\text { survival and fecundity rate of marine mammals and/or } \\
\text { increased mortality rate or emigration. }\end{array}$ & $\begin{array}{l}\text { Currey et al., 2007, 2009; Christiansen and } \\
\text { Lusseau, } 2015\end{array}$ \\
\hline $\begin{array}{l}\text { Declines in physical health through, e.g., pollutant } \\
\text { levels, injury or mortality rates }\end{array}$ & $\begin{array}{l}\text { - Increase in the incidence of mortalities and injuries of } \\
\text { marine mammals }\end{array}$ & $\begin{array}{l}\text { Knowlton and Kraus, 2001; Panigada et al., 2006; } \\
\text { Litz et al., 2007; Bechdel et al., 2009; Cagnazzi } \\
\text { et al., 2013a,b }\end{array}$ \\
\hline
\end{tabular}

${ }^{*}$ Potential trigger points will vary with between species and conservation status.

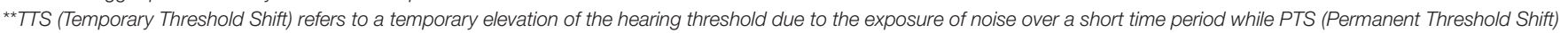
refers to permanent hearing loss due to prolonged exposure to noise (Richardson et al., 1995).

obtain acceptable power and precision to detect population trends.

Sensitivity analysis is an alternative to direct measures. Sensitivity analysis can be employed to forecast the probability that changes across time and space will have a certain impact (Tyne et al., 2016). Sensitivity analysis can be used to predict the point at which thresholds of triggers are being approached or crossed and therefore when intervention is required. Rarely are the actual ecological thresholds precisely known and a precautionary approach is necessary when using such predictive measures. Uncertainties may arise due to difficulties in predicting the precise boundaries of acceptable limits and these are reflected in the set safety margins of predictions. Scholes and Kruger (2011) noted that the key measure in predictions is not the point at which the threshold is intercepted, but the earliest point at which the change reaches the lower detectable safety margin. At this point, there should be sufficient notification that a threshold is being approached and early preventative measures can be activated (Scholes and Kruger, 2011).

Levels of acceptable and unacceptable change along with safety margins for indicators are not only informed by statistical inference and ecological values, but also by social and economic values (Scholes and Kruger, 2011). Accordingly, the limits of change may be set on societal values rather than system thresholds or ecological limits alone (e.g., zero mortality for an iconic species). This approach can lead to confusion and debate between stakeholders and management agencies about where the burden of proof lies (Nie and Schultz, 2012). We suggest that thresholds of change should initially be derived using the principle of sustainability, i.e., populations should not decline due to a development, and this is particularly important for threatened species. Any deviation from this-for whatever reasons-should err on the side of doing less harm to the environment.

\section{Obtain Baseline Information}

These initial four stages are then followed by the collection of baseline information that establishes pre-exposure measures and a point of reference to compare and evaluate changes over time (Nie and Schultz, 2012). It is essential that baseline information be robust and based on a defensible sampling design that is applied from the outset with sufficient time and budgetary resources to encompass the natural variation inherent in the indicator species at the impact site, e.g., changes in seasonal presence and abundance prior to exposure to the impact. A robust baseline combined with control sites reduces uncertainty and provides confidence in detecting and quantifying impacts specifically from activities associated with the project. Baseline data should be gathered from both control and impact sites prior to the implementation of project activities to enable counterfactual analysis during the constructional and operational phases in line with appropriate experimental designs, e.g., BACI (Block et al., 2001).

\section{Risk Analysis and Prioritization}

Risk analysis involves a detailed consideration of the likelihood and consequences of all potential hazards arising from each phase of the project to enable risk mitigation. This process is an integral part of the EIA process and should be completed before a project is approved and well before the construction phase commences. Assessment of risk is largely informed by empirical research and considers the temporal and spatial intensity and duration 
of any likely hazard. Risk assessment asks questions such as: "What is the likelihood that the marine mammals of interest will be exposed to the hazard?" "What is the consequence of the exposure?" "What is the level of uncertainty in this estimation?" Each of these questions is a key component of the risk analysis procedure and associated risk analysis framework, even though the actual framework will differ between marine mammal species and sites (Figure 2). For example, the exposure of highly mobile species to a coastal development is likely to be less than the exposure of species with localized and small home ranges that overlap with the impact site.

Mitigation, minimization and offset procedures and actions can be incorporated into the development conditions once the risks have been identified. Both the risks and the corresponding measures to minimize their impacts need to be clearly stated along with the associated limitations and uncertainties to maintain transparency and ensure appropriate management approaches and precautions (Suter, 2006; Grech et al., 2013).

Cumulative Impact Assessments (CIAs), the process of systematically analysing, evaluating or predicting cumulative environmental change (Spaling and Smit, 1993), are an integral tool in EIAs. Cumulative impacts can be assessed by either: (1) a measure of direct or indirect response to cumulative impact (e.g., change in distribution, fecundity, abundance) (Dubé et al., 2006); or (2) a prediction of impact (Halpern et al., 2007). CIAs require information on: the relative magnitude and

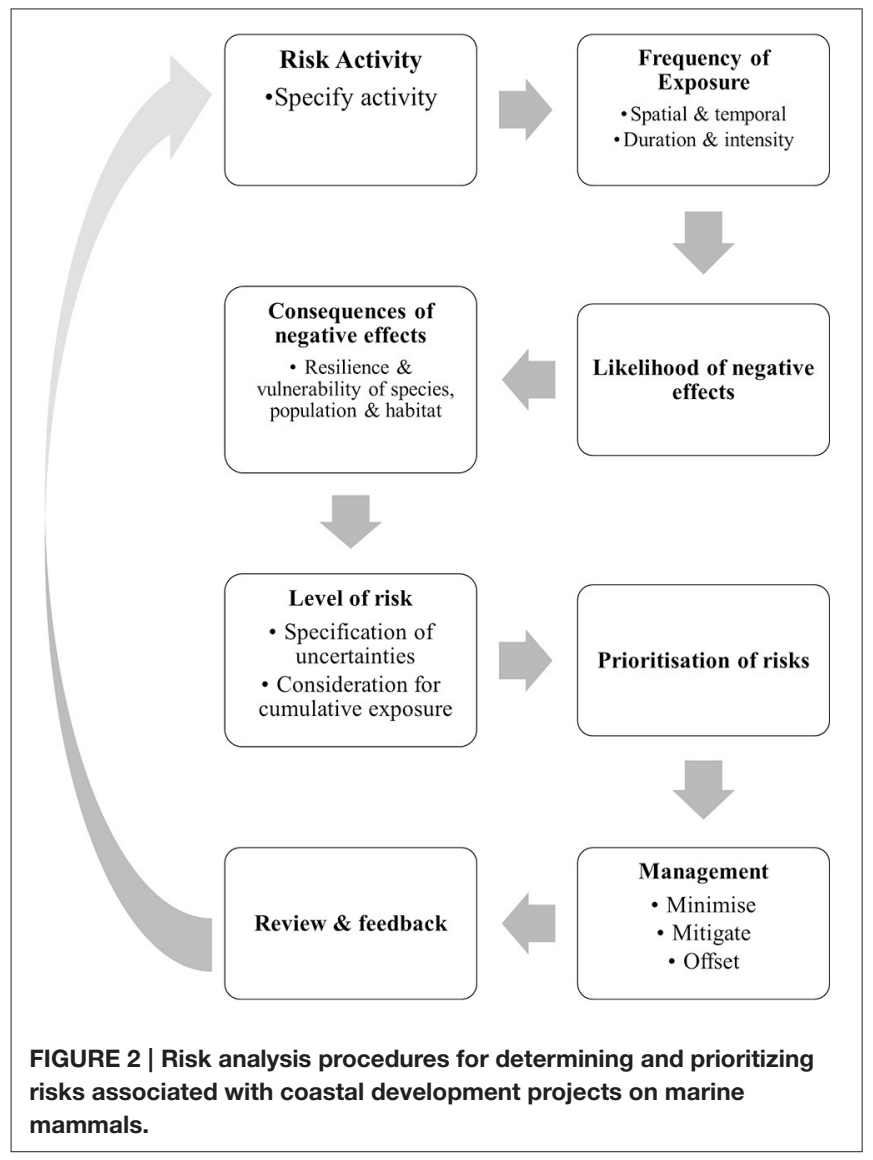

impact of pressures on the receiving environment; the spatiotemporal distribution of pressures and environmental features; and, the additive, synergistic or antagonistic interactions between multiple pressures (Grech et al., 2015). CIAs also require a holistic approach whereby the interacting pressures from one action (e.g., dredging) are considered in combination with past (e.g., unsustainable fishing), present (e.g., coastal development) and future (e.g., climate change) impacts. While our understanding the effect of cumulative interactions on marine mammals remains incomplete, we recommend that such data limitations be taken into account and that assessments proceed with these limitations, uncertainties and assumptions clearly stated.

\section{Project Approval/Decline}

Obtaining a thorough and robust ecological assessment on marine mammals from these aforementioned steps can then assist to provide guidance for decision makers, proponents and stakeholders regarding whether a project should be approved or declined. Combining the ecological, economic and social factors that constitute the overarching EIA, decision makers can then weigh the benefits and costs of a project in its entirety. In the case of an approved project, conditions can then be specified for ongoing monitoring, risk reduction and management procedures. The following steps provide guidance for these where marine mammals are concerned.

\section{Monitor and Validate}

Monitoring throughout the construction and operational phases of an approved project is vital where the potential impacts are likely to be substantial or have high levels of uncertainty (Sadler, 1996). Such monitoring is required to: (1) evaluate the impacts and measure indicators; (2) prevent environmental problems; (3) to address unforeseen changes or inadequate mitigation measures; (4) validate predictions; (5) provide feedback mechanisms relating to thresholds and effectiveness of mitigation; and (6) adjust management approaches (Sadler, 1996; Elliott, 2014). Unfortunately, rigorous and robust monitoring is rarely done and poorly-designed monitoring can lead to flawed recommendations. Lindenmayer et al. (2013) stress that monitoring programs should be designed for "rigorous quantification" to ensure the optimal ability to detect changes as early as possible. This approach involves systematic assessment of indicators and measures against thresholds or trigger points that are accompanied by pre-planned interventions and actions that are clearly articulated and integrated into project monitoring and planning.

When will limits of change result in a trigger response and what will be the action response? Figure 3 details the relationships between the monitoring and validation phase, the threshold triggers and management with guidance for decision making using examples and feedback loops. For example, an unacceptable change may be defined as any decrease in the abundance of a small (e.g., $\leq 100$ mature individuals) or already rapidly declining population of site-specific regional population of coastal dolphins. If systematic samples obtained during the construction phase indicated that there was a $2 \%$ loss (Perrin et al., 1994), this result would then lead to management 


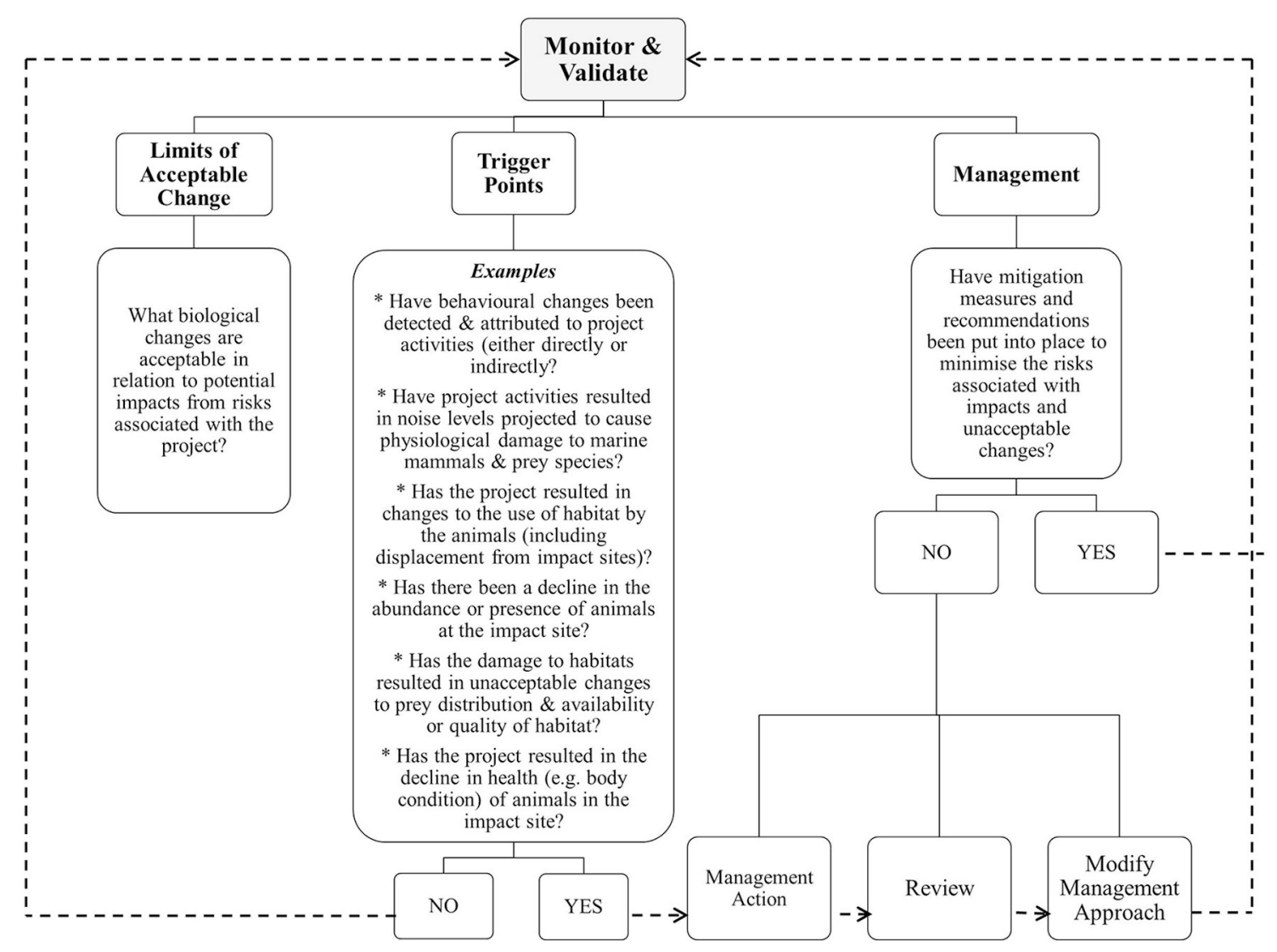

FIGURE 3 | Relationships between monitoring, trigger points as informed by limits of acceptable change and adaptive management actions. Note: dashed lines indicate feedback loops.

intervention and action along with review and modification of management and monitoring procedures. Adaptive management approaches should be flexible enough to not only implement intervention when required, but also to incorporate new learnings from the review process.

Short-term changes may not necessarily reflect long-term impacts and so monitoring programs need to operate for long enough to ensure that population responses can be detected (Block et al., 2001). Detectable changes in behavioral responses that can lead to changes in vital rates of marine mammal populations may be delayed and difficult to detect due to lag effects. The response time-lag differs greatly between species of marine mammals and depends on numerous factors such as life history parameters, behavioral plasticity and resilience (Brakes and Dall, 2016). Therefore, ongoing monitoring programs need to be carefully designed and apply appropriate sampling intervals and longevity to detect changes in vital rates.

\section{Recommendations and Adaptive Management}

Adaptive management frameworks are most appropriate to apply in the context of monitoring and minimized the impacts of projects on marine mammals as they allow for integration and flexibility (Higham et al., 2009) and provide a structured approach for systematic and continuous evaluation of: (1) monitoring results against project objectives; (2) measuring the effectiveness of actions in place to minimize or offset impacts; (3) opportunity to adjust management actions to address shortfalls, and (4) integration of new knowledge, at regular and pre-defined intervals (Block et al., 2001; Nie and Schultz, 2012). Regular re-evaluation allows for the predictions of project impacts to be assessed and adjustments made enabling uncertainties to be reduced over time (Block et al., 2001; Higham et al., 2009; Nie and Schultz, 2012).

Management actions need to be well articulated and related to each trigger point. Safety margins around trigger thresholds must be defined in advance along with actions to be taken if the trigger point (or its safety margin) is crossed. Outlining categories that define how close thresholds or trigger points are at a given point in the monitoring program can provide a useful approach to inform management actions. Scholes and Kruger (2011) describe a multi-stage warning system that reflects levels of "potential concern" and incorporates system, management and monitoring response intervals. The system integrates levels of uncertainty within safety margins and predicted timescales where a certain impact may occur. Furthermore, the multi-stage system can theoretically provide early warning systems for unwanted changes, for example, using a "traffic light" warning system, an amber alert indicates that the lower safety margins are being 
approached, but have not yet been crossed and management intervention can be put into action (Scholes and Kruger, 2011). Similar systems could be developed and applied to marine mammal monitoring, especially in cases where there is high uncertainty to ensure management actions take place before acute effects arise.

In many cases, the outcomes from EIAs and monitoring programs are confidential to the developer and/or the governing agency. This lack of transparency stifles progress in advancing the understanding of impacts of coastal development activities on marine mammal species and hinders the effectiveness of mitigation measures at the development site and other locations. Mistakes are not identified creating tensions between stakeholders and the general public, particularly for controversial projects. We recommend early involvement and consultation with stakeholders to provide for a more informed process. Such integration along with the inclusion of an independent review process, can also improve methodologies in addition to transparency in the decision making process (Grech et al., 2013).

\section{CONCLUSIONS}

Determining and monitoring the effect of coastal development on marine mammals is challenging for a number of reasons: (1) the impacts of coastal developments often occur at local scales that do not match the ecological scales of marine mammals making it very difficult to identify appropriate controls; (2) the imperative for development rarely allows time for adequate baseline studies; (3) it is difficult to extrapolate the effect of short-term behavioral responses into long-term population impacts; (4) local marine mammal populations tend to be small making it difficult to design monitoring with sufficiently high statistical power to detect change within useful timeframes; (5) most marine mammal species are inherently difficult to study especially experimentally; (6) long-lived marine mammals are susceptible to cumulative impacts and it can be difficult to isolate the effects of coastal development from other impacts. Approaches taken that apply best practice will contribute to addressing these challenges within the logistical bounds of the project where limitations and uncertainties are clearly stated.

We have provided a synthesis and framework that sets a foundation for industry and policy makers in relation to biological components of EIAs, to establish a standard of practice with the aim to minimize harm to marine mammals from coastal developments. It encourages the use of and application of EIAs as an overarching mechanism for which this framework can be applied. We recommend that project objectives be explicit and realistic and the methodologies based on best practice

\section{REFERENCES}

Allen, S. J., Tyne, J. A., Kobryn, H. T., Bejder, L., Pollock, K. H., and Loneragan, N. R. (2014). Patterns of dolphin bycatch in a North-Western Australian trawl fishery. PLoS ONE 9:e93178. doi: 10.1371/journal.pone.0093178

Bain, D. E., and Dahlheim, M. E. (1994). "Effects of masking noise on detection thresholds of killer whales," in Marine Mammals and the Exxon Valdez, ed T. R. Loughlin (San Diego, CA: Academic Press, Inc.), 243-256. with their limitations and underlying assumptions explicitly acknowledged. While resource allocation for each phase of a project can be limited, it should be sufficient to provide adequate statistical power to apply appropriate survey design to determine the impact of development on populations of marine mammals. Trigger points and indicators must be clearly defined and monitoring needs to be designed to detect trigger thresholds whilst incorporating safety margins that acknowledge the levels of uncertainty. Stakeholder agreement on the limits of acceptable change can be difficult to obtain, however, differences and conflicts need to be addressed and overcome a priori. Decision making and management actions should be transparent and address levels of uncertainty whilst applying precaution where these levels are high and where the impact of a project can affect species and populations of marine mammals.

A large proportion of marine mammal species are classified as data deficient or threatened (vulnerable, endangered or critically endangered) globally. This situation, coupled with the growing evidence of the susceptibility of many marine mammal species to a range of human activities, reinforces the need for at risk or vulnerable coastal marine mammal populations to be appropriately represented and assessed in the EIA process.

\section{AUTHOR CONTRIBUTIONS}

Original concept conceived by HM and $\mathrm{PH}$. Manuscript prepared by $\mathrm{EH}$, critical review, re-drafting and editorial input by $\mathrm{RH}, \mathrm{PH}$, LB, LOB, AG, FC, and HM.

\section{FUNDING}

This project was funded by an Australian Marine Mammal Centre grant to Professor HM and Professor PH. Further funding support was provided by the Southern Cross University Marine Ecology Research Centre.

\section{ACKNOWLEDGMENTS}

The authors would like to acknowledge Karin Forney, Tim Gerrodette, Robert McCauley and Michael McCarthy, who were key contributors to the workshop and subsequent report and the support of the Society for Marine Mammals for the facilitation of the project workshop at the 20th Biennial Conference on the Biology of Marine Mammals, 2013. The authors thank the 57 workshop participants who provided valuable insights. Additional in-kind support was also received from Dolphin Research Australia Inc. 
Bejder, L., Hodgson, A., Loneragan, N. R., and Allen, S. J. (2012). Coastal dolphins in North-Western Australia: the need for re-evaluation of species listings and short-comings in the environmental impact assessment process. Pac. Conserv. Biol. 18, 22-25. doi: 10.1071/PC120022

Bejder, L., Samuels, A., Whitehead, H., and Gales, N. (2006a). Interpreting shortterm behavioural responses to disturbance with a longitudinal perspective. Anim. Behav. 72, 1149-1158. doi: 10.1016/j.anbehav.2006.04.003

Bejder, L., Samuels, A., Whitehead, H., Gales, N., Mann, J., Connor, R. C., et al. (2006b). Decline in relative abundance of bottlenose dolphins exposed to long-term disturbance. Conserv. Biol. 20, 1791-1798. doi: 10.1111/j.1523-1739.2006.00540.x

Block, W., Franklin, A., Ward, J., Ganey, J., and White, G. (2001). Design and implementation of monitoring studies to evaluate the success of ecological restoration on wildlife. Restor. Ecol. 9, 293-303. doi: 10.1046/j.1526-100x.2001.009003293.x

Brakes, P., and Dall, S. (2016). Marine mammal behavior: a review of conservation implications. Front. Mar. Sci. 3, 1-15. doi: 10.3389/fmars.2016.00087

Braulik, G., Noureen, U., Arshad, M., and Reeves, R. (2015). Review of status, threats, and conservation management options for the endangered Indus River blind dolphin. Biol. Conserv. 192, 30-41. doi: 10.1016/j.biocon.2015. 09.008

Buckland, S. T., Anderson, D. R., Burnham, K. P., and Laake, J. L. (2005). Distance Sampling. New Jersey: Wiley Online Library.

Cagnazzi, D., Fossi, M. C., Parra, G. J., Harrison, P. L., Maltese, S., Coppola, D., et al. (2013a). Anthropogenic contaminants in Indo-Pacific humpback and Australian snubfin dolphins from the central and southern Great Barrier Reef. Environ. Pollut. 182, 490-494. doi: 10.1016/j.envpol.2013.08.008

Cagnazzi, D., Parra, G. J., Westley, S., and Harrison, P. L. (2013b). At the heart of the industrial boom: Australian Snubfin Dolphins in the Capricorn Coast, Queensland, need urgent conservation action. PLoS ONE 8:e56729. doi: 10.1371/journal.pone.0056729

Castilla, J. (1999). Coastal marine communities: trends and perspectives from human-exclusion experiments. Trends Ecol. Evol. 14, 280-283. doi: 10.1016/S0169-5347(99)01602-X

Christiansen, F., and Lusseau, D. (2015). Linking behavior to vital rates to measure the effects of non-lethal disturbance on wildlife. Conserv. Lett. 8, 424-431. doi: $10.1111 /$ conl.12166

Christiansen, F., Rasmussen, M. H., and Lusseau, D. (2013). Inferring activity budgets in wild animals to estimate the consequences of disturbances. Behav. Ecol. 24, 1415-2425. doi: 10.1093/beheco/art086

Cook, P. F., Reichmuth, C., Rouse, A. A., Libby, L. A., Dennison, S. E., Carmichael, O. T., et al. (2015). Algal toxin impairs sea lion memory and hippocampal connectivity, with implications for strandings. Science 350, 1545-1547. doi: 10.1126/science.aac5675

Crain, C. M., Kroeker, K., and Halpern, B. S. (2008). Interactive and cumulative effects of multiple human stressors in marine systems. Ecol. Lett. 11, 1304-1315. doi: 10.1111/j.1461-0248.2008.01253.x

Cubero-Pardo, P., Donovan, C., and Urbán-Ramírez, J. (2011). A proposal to define vulnerability of cetacean areas to human development: variables and analysis procedures applied to the Gulf of California. Aquat. Conserv. Mar. Freshw. Ecosyst. 21, 433-447. doi: 10.1002/aqc.1205

Currey, R., Dawson, S. M., Slooten, E., Schneider, K., Lusseau, D., Boisseau, O. J., et al. (2009). Survival rates for a declining population of bottlenose dolphins in Doubtful Sound, New Zealand: an information theoretic approach to assessing the role of human impacts. Aquat. Conserv. Mar. Freshw. Ecosyst. 19, 658-670. doi: 10.1002/aqc.1015

Currey, R., Dawson, S., and Slooten, E. (2007). New abundance estimates suggest Doubtful Sound bottlenose dolphins are declining. Pac. Conserv. Biol. 13, 274-282. doi: 10.1071/PC070274

Delport, T. C., Asher, A. J., Beaumont, L. J., Webster, K. N., Harcourt, R. G., and Power, M. L. (2014). Giardia duodenalis and Cryptosporidium occurrence in Australian sea lions (Neophoca cinerea) exposed to varied levels of human interaction. Int. J. Parasitol. Parasites Wildl. 3, 269-275. doi: 10.1016/j.ijppaw.2014.09.001

Delport, T. C., Harcourt, R. G., Beaumont, L. J., Webster, K. N., and Power, M. L. (2015). Molecular detection of antibiotic-resistance determnants in Escherichia coli isolated from the endangered Australian Sea Lion (Neophoca cinerea). J. Wildl. Dis. 51, 555-563. doi: 10.7589/2014-08-200 de Souza Albuquerque, N., and da Silva Souto, A. (2013). Motorboat noise can potentially mask the whistle sound of estuarine dolphins (Sotalia guianensis). Ethnobiol. Conserv. 2, 1-15.

Dolman, S., and Simmonds, M. (2010). Towards best environmental practice for cetacean conservation in developing Scotland's marine renewable energy. Mar. Policy 34, 1021-1027. doi: 10.1016/j.marpol.2010.02.009

Dubé, M., Johnson, B., Dunn, G., Culp, J., Cash, K., Munkittrick, K., et al. (2006). Development of a new approach to cumulative effects assessment: a northern river ecosystem example. Environ. Monit. Assess. 113, 87-115. doi: 10.1007/s10661-005-9098-0

Efford, M., and Dawson, D. (2012). Occupancy in continuous habitat. Ecosphere 3, 1-15. doi: 10.1890/ES11-00308.1

Elliott, M. (2014). Environmental Impact Assessment in Australia: Theory and Practice, 6th Edn. Leichhardt, NSW: Federation Press.

Erbe, C. (2012). "Effects of underwater noise on marine mammals," in The Effects of Noise on Aquatic Life, ed A. Popper and A. Hawkins (New York, NY: Springer), $17-22$.

Evans, P. G. (2009). "Habitat pressures," in Encyclopedia of Marine Mammals, 2nd Edn., eds W. F. Perrin, B. Wursig, and J. G. M. Thewissen (San Diego, CA: Academic Press; Elsevier), 521-523.

Fleishman, E., Costa, D. P., Harwood, J., Kraus, S., Moretti, D., New, L. F., et al. (2016). Monitoring population-level responses of marine mammals to human activities. Mar. Mammal Sci. 32, 1004-1021. doi: 10.1111/mms.12310

Foote, A. D., Osborne, R. W., and Hoelzel, A. R. (2004). Whale-call response to masking boat noise. Nature 428, 910. doi: 10.1038/428910a

Ford, J. K., Ellis, G. M., Olesiuk, P. F., and Balcomb, K. C. (2010). Linking killer whale survival and prey abundance: food limitation in the oceans' apex predator? Biol. Lett. 6, 139-142. doi: 10.1098/rsbl.2009.0468

Frihy, O. (2001). The necessity of environmental impact assessment (EIA) in implementing coastal projects: lessons learned from the Egyptian Mediterranean Coast. Ocean Coast. Manage. 44, 489-516. doi: 10.1016/S0964-5691(01)00062-X

Gilpin, A. (1995). Environmental Impact Assessment: Cutting Edge for the 21st Century. Cambridge, UK: Cambridge University Press.

Grech, A., Bos, M., Brodie, J., Coles, R., Dale, A., Gilbert, R., et al. (2013). Guiding principles for the improved governance of port and shipping impacts in the Great Barrier Reef. Mar. Pollut. Bull. 75, 8-20. doi: 10.1016/j.marpolbul.2013.07.013

Grech, A., and Marsh, H. (2008). Rapid assessment of risks to a mobile marine mammal in an ecosystem-scale marine protected area. Conserv. Biol. 22, 711-720. doi: 10.1111/j.1523-1739.2008.00923.x

Grech, A., Pressey, R. L., and Day, J. C. (2015). Coal, cumulative impacts, and the great barrier reef. Conserv. Lett. 9, 200-207. doi: 10.1111/conl.12208

Hagihara, R., Jones, R., Grech, A., Lanyon, J., Sheppard, J., and Marsh, H. (2014). Improving population estimates by quantifying diving and surfacing patterns: a dugong example. Mar. Mammal. Sci. 30, 348-366. doi: 10.1111/mms.12041

Halpern, B. S., Selkoe, K. A., Micheli, F., and Kappel, C. V. (2007). Evaluating and ranking the vulnerability of global marine ecosystems to anthropogenic threats. Conserv. Biol. 21, 1301-1315. doi: 10.1111/j.1523-1739.2007.00752.x

Harcourt, R., Aurioles, D., and Sanchez, J. (1994). Entanglement of California sea lions at los islotes, Baja California Sur, México. Mar. Mammal. Sci. 10, 122-125. doi: 10.1111/j.1748-7692.1994.tb00399.x

Harwood, J. (2001). Marine mammals and their environment in the twenty-first century. J. Mammal. 82, 630-640. doi: 10.1644/1545-1542(2001)082<0630:MMATEI > 2.0.CO;2

Hauser, C. E., and McCarthy, M. A. (2009). Streamlining 'search and destroy': costeffective surveillance for invasive species management. Ecol. Lett. 12, 683-692. doi: 10.1111/j.1461-0248.2009.01323.x

Hawkins, E. R., and Gartside, D. F. (2008). Social and behavioural characteristics of indo-pacific bottlenose dolphins (Tursiops aduncus) in northern New South Wales, Australia. Aust. Mammal. 30, 71-82. doi: 10.1071/AM08009

Higham, J., Bejder, L., and Lusseau, D. (2009). An integrated and adaptive management model to address the long-term sustainability of tourist interactions with cetaceans. Environ. Conserv. 35, 294-302. doi: $10.1017 /$ S0376892908005249

Hughes, R.,Williams, S., Duarte, C., Heck, K., and Waycott, M. (2009). Associations of concern: declining seagrasses and threatened dependent species. Front. Ecol. Environ. 7, 242-246. doi: 10.1890/080041 
Jefferson, T. A., Hung, S. K., and Würsig, B. (2009). Protecting small cetaceans from coastal development: Impact assessment and mitigation experience in Hong Kong. Mar. Policy 33, 305-311. doi: 10.1016/j.marpol.2008.07.011

Jepson, P. D., Bennett, P. M., Deaville, R., Allchin, C. R., Baker, J. R., and Law, R. J. (2005). Relationships between polychlorinated biphenyls and health status in harbor porpoises (Phocoena phocoena) stranded in the United Kingdom. Environ. Toxicol. Chem. 24, 238-248. doi: 10.1897/03-663.1

Jepson, P. D., Deaville, R., Barber, J. L., Aguilar, À., Borrell, A., Murphy, S., et al. (2016). PCB pollution continues to impact populations of orcas and other dolphins in European waters. Sci. Rep. 6:18573. doi: 10.1038/srep18573

Knowlton, A. R., and Kraus, S. D. (2001). Mortality and serious injury of northern right whales (Eubalaena glacialis) in the western North Atlantic Ocean. J. Cetacean Res. Manage. 2, 193-208.

Krahn, M., Wade, P., Kalinowski, S., Dahlheim, M., Taylor, B., Hanson, B., et al. (2002). Status review under the endangered species act: southern resident killer whales (Orcinus orca) 2002. NOAA Tech. Memo NMFS-NWFSC 54, 159.

Laist, D., Knowlton, A. R., Mead, J. C., Collet, A. S., and Podesta, M. (2001). Collisions between ships and whales. Mar. Mammal. Sci. 17, 35-75. doi: 10.1111/j.1748-7692.2001.tb00980.x

Lindenmayer, D. B., Piggott, M. P., and Wintle, B. A. (2013). Counting the books while the library burns: why conservation monitoring programs need a plan for action. Front. Ecol. Environ. 11, 549-555. doi: 10.1890/120220

Litz, J. A., Garrison, L. P., Fieber, L. A., Martinez, A., Contillo, J. P., and Kucklick, J. R. (2007). Fine-scale spatial variation of persistent organic pollutants in bottlenose dolphins (Tursiops truncatus) in Biscayne Bay, Florida. Environ. Sci. Technol. 41, 7222-7228. doi: 10.1021/es070440r

Lotze, H. K., Lenihan, H. S., Bourque, B. J., Bradbury, R. H., Cooke, R. G., Kay, M. C., et al. (2006). Depletion, degradation, and recovery potential of estuaries and coastal seas. Science 312, 1806-1809. doi: 10.1126/science.1128035

Lusseau, D. (2004). The hidden cost of tourism: detecting long-term effects of tourism using behavioral information. Ecol. Soc. 9, 1-15. doi: 10.5751/ES-00662-0902r01

Lusseau, D., Bain, D. E., Williams, R., and Smith, J. C. (2009). Vessel traffic disrupts the foraging behavior of southern resident killer whales Orcinus orca. Endanger. Species Res. 6, 211-221. doi: 10.3354/esr00154

Lusseau, D., and Bejder, L. (2007). The long-term consequences of short-term responses to disturbance experiences from Whalewatching Impact Assessment. Int. J. Comp. Psychol. 20, 228-236.

Lusseau, D., Kraus, S., McMahon, C. R., Robinson, P. W., Schick, R. S., Schwarz, L. K., et al. (2014). Using short-term measures of behaviour to estimate longterm fitness of southern elephant seals. Mar. Ecol. Prog. Ser. 496, 99-108. doi: 10.3354/meps 10547

Lusseau, D., Slooten, L., Rohan, J., and Currey, C. (2006). Unsustainable dolphinwatching tourism in Fiordland, New Zealand. Tourism Mar. Environ. 3, 173-178. doi: 10.3727/154427306779435184

MacKenzie, D. I., Nichols, J. D., Royle, J. A., Pollock, K. H., Bailey, L. L., and Hines, J. E. (2006). Occupancy Estimation and Modeling: Inferring Patterns and Dynamics of Species Occurrence. London: Elsevier Academic Press.

MacKenzie, D. L., and Clement, D. M. (2014). Abundance and Distribution of ECSI Hector's Dolphin. Report for Ministry for Primary Industries, Wellington.

Mannocci, L., Dabin, W., Augeraud-Véron, E., Dupuy, J., Barbraud, C., and Ridoux, V. (2012). Assessing the impact of bycatch on dolphin populations: the case of the common dolphin in the eastern North Atlantic. PLoS ONE 7:e32615. doi: 10.1371/journal.pone.0032615

Marsh, H., O'Shea, T. J., and Reynolds, J. E. III. (2011). Ecology and Conservation of the Sirenia: Dugongs and Manatees. Cambridge, UK: Cambridge University Press.

Marsh, H., and Sinclair, D. F. (1989). Correcting for visibility bias in strip transect aerial surveys of aquatic fauna. J. Wildl. Manage. 53, 1017-1024. doi: $10.2307 / 3809604$

Miller, D. L., Burt, M. L., Rexstad, E. A., and Thomas, L. (2013). Spatial models for distance sampling data: recent developments and future directions. Methods Ecol. Evol. 4, 1001-1010. doi: 10.1111/2041-210X.12105

Moore, A. L., and McCarthy, M. A. (2016). Optimizing ecological survey effort over space and time. Methods Ecol. Evol. 7, 891-899. doi: 10.1111/2041-210X.12564

Morton, A., and Symonds, H. (2002). Displacement of Orcinus orca (L.) by high amplitude sound in British Columbia, Canada. ICES J. Mar. Sci. 59, 71-80. doi: $10.1006 /$ jmsc.2001.1136
New, L. F., Hall, A. J., Harcourt, R., Kaufman, G., Parsons, E. C. M., Pearson, H. C., et al. (2015). The modelling and assessment of whale-watching impacts. Ocean Coast. Manage. 30, e7. doi: 10.1016/j.ocecoaman.2015.04.006

Newson, S., Mendes, S., Crick, H., Dulvy, N., Houghton, J., Hays, G., et al. (2009). Indicators of the impact of climate change on migratory species. Endanger. Species Res. 7, 101-113. doi: 10.3354/esr00162

Nie, M. A., and Schultz, C. A. (2012). Decision-making triggers in adaptive management. Conserv. Biol. 26, 1137-1144. doi: 10.1111/j.1523-1739.2012.01915.x

Page, B., McKenzie, J., McIntosh, R., Baylis, A., Morrissey, A., Calvert, N., et al. (2004). Entanglement of Australian sea lions and New Zealand fur seals in lost fishing gear and other marine debris before and after Government and industry attempts to reduce the problem. Mar. Pollut. Bull. 49, 33-42. doi: 10.1016/j.marpolbul.2004.01.006

Panigada, S., Pesante, G., Zanardelli, M., Capoulade, F., Gannier, A., and Weinrich, M. (2006). Mediterranean fin whales at risk from fatal ship strikes. Mar. Pollut. Bull. 52, 1287-1298. doi: 10.1016/j.marpolbul.2006.03.014

Perrin, W., Donovan, G., and Barlow, J. (1994). Gillnets and Cetaceans: Incorporating the Proceedings of the Symposium and Workshop on the Mortality of Cetaceans in Passive Fishing Nets and Traps. Report to the International Whaling Commission, Cambridge: International Whaling Commission.

Pirotta, E., Laesser, B. E., Hardaker, A., Riddoch, N., Marcoux, M., and Lusseau, D. (2013). Dredging displaces bottlenose dolphins from an urbanised foraging patch. Mar. Pollut. Bull. 74, 396-402. doi: 10.1016/j.marpolbul.2013.06.020

Pollock, K., Marsh, H., Lawler, I., and Alldredge, M. (2006). Modelling availability and perception processes for strip and line transects: an application to dugong aerial surveys. J. Wildl. Manage. 70, 255-262. doi: 10.2193/0022541X(2006)70[255:EAAIHE]2.0.CO;2

Read, A. J. (2008). The looming crisis: interactions between marine mammals and fisheries. J. Mammal. 89, 541-548. doi: 10.1644/07-MAMM-S-315R1.1

Reeves, R. R., Dalebout, M. L., Jefferson, T. A., Karczmarski, L., Laidre K., O'Corry-Crowe, G., et al. (2008). "Sousa chinensis (Eastern Taiwan Strait subpopulation)," in The IUCN Red List of Threatened Species 2008: e.T133710A3873928. Available online at: http://www.iucnredlist.org

Richardson, W. J., Greene, C. R., Malme, C. I., and Thomson, D. H. (1995). Marine Mammals and Noise. San Diego, CA: Academic Press, Inc.

Ross, P. S. (2006). Fireproof killer whales (Orcinus orca): flame-retardant chemicals and the conservation imperative in the charismatic icon of British Columbia, Canada. Can. J. Fish. Aquat. Sci. 63, 224-234. doi: 10.1139/f05-244

Sadler, B. (1996). International Study of the Effectiveness of Environmental Assessment. Final Report: Environmental Assessment in a Changing World: Evaluating Practice to Improve Performance, Canadian Environmental Assessment Agency.

Schipper, J., Chanson, J., Chiozza, F., Cox, N., Hoffmann, M., Katariya, V., et al. (2008). The status of the world's land and marine mammals: diversity, threat, and knowledge. Science 322, 225-230. doi: 10.1126/science.1165115

Schlundt, C. E., Finneran, J. J., Carder, D. A., and Ridgway, S. H. (2000). Temporary shift in masked hearing thresholds of bottlenose dolphins, Tursiops truncatus, and white whales, Delphinapterus leucas, after exposure to intense tones. J. Acoust. Soc. Am. 107, 3496-3508. doi: 10.1121/1.429420

Scholes, R., and Kruger, J. (2011). A framework for deriving and triggering thresholds for management intervention in uncertain, varying and time-lagged systems. Koedoe 53, 179-186. doi: 10.4102/koedoe.v53i2.987

Senécal, P., Goldsmith, B., Conover, S., Sadler, B., and Brown, K. (1999). Principles of Environmental Impact Assessment Best Practice. Fargo, ND: Special Publication, International Association for Impact Assessment.

Small, C., and Nicholls, R. (2003). A global analysis of human settlement in coastal zones. J. Coast. Res. 19, 584-599.

Smith, H., Frère, C., Kobryn, H., and Bejder, L. (2016). Dolphin sociality, distribution and calving as important behavioural patterns informing management. Anim. Conserv. 19, 462-471. doi: 10.1111/acv.12263

Spaling, H., and Smit, B. (1993). Cumulative environmental change: conceptual frameworks, evaluation approaches, and institutional perspectives. Environ. Manage. 17, 587-600. doi: 10.1007/BF02393721

Steckenreuter, A., Harcourt, R., and Möller, L. (2011). Distance does matter: close approaches by boats impede feeding and resting behaviour of Indo-Pacific bottlenose dolphins. Wildl. Res. 38, 455-463. doi: 10.1071/ WR11048 
Suter, G. W. (2006). Ecological Risk Assessment, 2nd Edition. Boca Raton, FL: CRC Press.

Taylor, B., Martinez, M., Gerrodette, T., Barlow, J., and Hrovat, Y. (2007). Lessons from monitoring trends in abundance of marine mammals. Mar. Mammal. Sci. 23, 157-175. doi: 10.1111/j.1748-7692.2006.00092.x

Turvey, S. T., Pitman, R. L., Taylor, B. L., Barlow, J., Akamatsu, T., Barrett, L. A., et al. (2007). First human-caused extinction of a cetacean species? Biol. Lett. 3, 537-540. doi: 10.1098/rsbl.2007.0292

Tyack, P. L. (2008). Implications for marine mammals of large-scale changes in the marine acoustic environment. J. Mammal. 89, 549-558. doi: 10.1644/07-MAMM-S-307R.1

Tyne, J., Johnston, D., Rankin, R. T., Loneragan, N., and Bejder, L. (2015). The importance of spinner dolphin (Stenella longirostris) resting habitat: implications for management. J. Appl. Ecol. 52, 621-630. doi: 10.1111/1365-2664.12434

Tyne, J., Loneragan, N., Johnston, D., Pollock, K., Williams, R., and Bejder, L. (2016). Evaluating monitoring methods for cetaceans. Biol. Conserv. 201, 252-260. doi: 10.1016/j.biocon.2016.07.024

Underwood, A. J. (1994). On beyond BACI: sampling designs that might reliably detect environmental disturbances. Ecol. Appl. 4, 3-15. doi: 10.2307/1942110

Van Bressem, M. F., Van Waerebeek, K., and Raga, J. A. (1999). A review of virus infections of cetaceans and the potential impact of morbilliviruses, poxviruses and papillomaviruses on host population dynamics. Dis. Aquat. Org. 38, 53-65. doi: $10.3354 /$ dao038053

Vlachos, E. (1985). “Assessing long-range cumulative impacts," in Environmental Impact Assessment, Technology Assessment, and Risk Analysis, Vol. 4, eds V. T. Covello, J. 1. L. Mumpower, P. M. Stallen, and V. R. R. Uppuluri (Berlin; Heidelberg: Springer), 49-80.

Wade, P., Reeves, R., and Mesnick, S. (2012). Social and behavioural factors in cetacean responses to overexploitation: are odontocetes less "resilient" than mysticetes? J. Mar. Biol. 2012, 1-15. doi: 10.1155/2012/ 567276

Wang, D., Zhang, X., Wang, K., Wei, Z., Wursig, B., Braulik, G. T., et al. (2006). Conservation of the baiji: no simple solution. Conserv. Biol. 20, 623-625. doi: 10.1111/j.1523-1739.2006.00471.x

Wang, J. Y., Chu Yang, S., Hung, S. K., and Jefferson, T. A. (2007). Distribution, abundance and conservation status of the eastern Taiwan Strait population of Indo-Pacific humpback dolphins, Sousa chinensis. Mammalia 71, 157-165. doi: 10.1515/MAMM.2007.032

Watson-Capps, J. J., and Mann, J. (2005). The effects of aquaculture on bottlenose dolphin (Tursiops sp.) ranging in Shark Bay, Western Australia. Biol. Conserv. 124, 519-526. doi: 10.1016/j.biocon.2005.03.001

Wells, R. S., and Scott, M. D. (1997). Seasonal incidence of boat strikes on bottlenose dolphins near Sarasota, Florida. Mar. Mammal. Sci. 13, 475-480. doi: 10.1111/j.1748-7692.1997.tb00654.x

Williams, R., Lusseau, D., and Hammond, P. S. (2006). Estimating relative energetic costs of human disturbance to killer whales (Orcinus orca). Biol. Conserv. 133, 301-311. doi: 10.1016/j.biocon.2006.06.010

Williams, R., and O'Hara, P. (2010). Modelling ship strike risk to fin, humpback and killer whales in British Columbia, Canada. J. Cetacean Res. Manage. 11, $1-8$.

Wilson, B., Hammond, P. S., and Thompson, P. M. (1999). Estimating size and assessing trends in a coastal bottlenose dolphin population. Ecol. Appl. 9, 288-300. doi: 10.1890/1051-0761(1999)009[0288:ESAATI]2.0.CO;2

Wood, C. (2003). Environmental Impact Assessment: A Comparative Review. Prentice Hall, NJ: Pearson Hall Publishing.

Wood, S. (2006). Generalized Additive Models: An introduction with R. Boca Raton, FL: CRC Press.

Zhang, X., Wang, D., Liu, R., Wei, Z., Hua, Y., Wang, Y., et al. (2003). The Yangtze River dolphin or baiji (Lipotes vexillifer): population status and conservation issues in the Yangtze River, China. Aquat. Conserv. Mar. Freshw. Ecosyst. 13, 51-64. doi: $10.1002 /$ aqc.547

Conflict of Interest Statement: The authors declare that the research was conducted in the absence of any commercial or financial relationships that could be construed as a potential conflict of interest.

Copyright (C) 2017 Hawkins, Harcourt, Bejder, Brooks, Grech, Christiansen, Marsh and Harrison. This is an open-access article distributed under the terms of the Creative Commons Attribution License (CC BY). The use, distribution or reproduction in other forums is permitted, provided the original author (s) or licensor are credited and that the original publication in this journal is cited, in accordance with accepted academic practice. No use, distribution or reproduction is permitted which does not comply with these terms. 